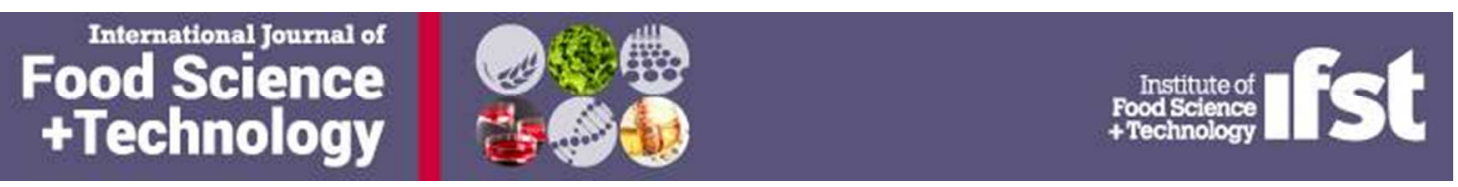

\title{
Spray drying conditions for orange juice incorporated with lactic acid bacteria
}

\begin{tabular}{|r|l|}
\hline Journal: & International Journal of Food Science and Technology \\
\hline Manuscript ID & IJFST-2016-21762.R1 \\
\hline Manuscript Type: & Original Manuscript \\
\hline Complete List of Authors: & $\begin{array}{l}\text { Barbosa, Joana; Universidade Catolica Portuguesa Centro Regional do } \\
\text { Porto, CBQF } \\
\text { Brandão, Teresa; UCP, CBQF } \\
\text { Teixeira, Paula; UCP, CBQF }\end{array}$ \\
\hline Keywords: & Probiotics, Spray Drying, Fruit Juices \\
\hline \multicolumn{2}{|c}{} \\
\hline
\end{tabular}




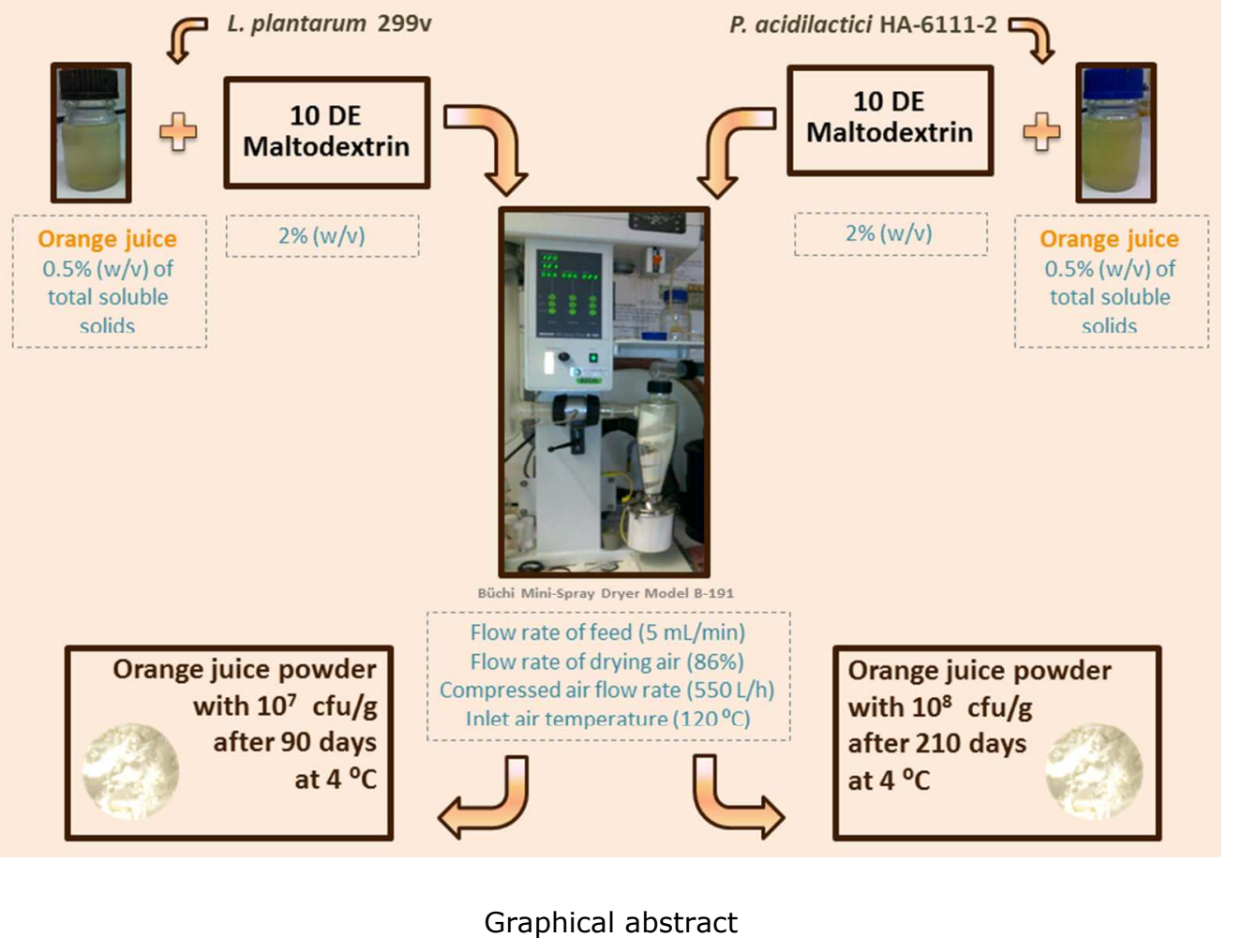

$254 \times 190 m m(96 \times 96$ DPI) 
1 Spray drying conditions for orange juice incorporated with lactic acid bacteria

2

3 Barbosa, J., Brandão, T.R.S. and *Teixeira, P.

4

5 Universidade Católica Portuguesa, CBQF - Centro de Biotecnologia e Química Fina -

6 Laboratório Associado, Escola Superior de Biotecnologia, Rua Arquiteto Lobão Vital, Apartado

$7 \quad 2511,4202-401$ Porto, Portugal

8

9

10 Running title: Probiotic orange juice powder

11

12

13

14

15

16

17

18

19

20 Correspondence: Paula Teixeira, E-mail: pcteixeira@porto.ucp.pt

21 


\section{Abstract}

23 This work aimed to develop an orange juice powder by spray drying with lactic acid bacteria 24 (Lactobacillus plantarum 299v and Pediococcus acidilactici HA-6111-2), testing their survival 25 both during drying and storage (room temperature and $4{ }^{\circ} \mathrm{C}$ ). Initially, the best conditions for 26 spray drying were chosen to allow the best survival of each LAB: i) inlet air temperature of 120

$27{ }^{\circ} \mathrm{C}$ and ii) 0.5:2 ratio of the orange juice soluble solids and drying agent added (prebiotics: 10DE 28 maltodextrin or gum Arabic). Survival of LAB was not affected by drying process and it was 29 higher when cultures were stored at $4{ }^{\circ} \mathrm{C}$. A slightly higher protection was conferred by $10 \mathrm{DE}$ 30 maltodextrin, in the case of L. plantarum and at $4{ }^{\circ} \mathrm{C}$. Pediococcus acidilactici was more resistant 31 during storage at $4{ }^{\circ} \mathrm{C}$, with logarithmic reductions lower than 1 log-unit. It was demonstrated 32 that it is possible to produce a functional non-dairy product, orange juice powder supplemented 33 with prebiotic compounds, containing viable LAB for at least 7 months, when stored at $4{ }^{\circ} \mathrm{C}$.

36 Keywords: Spray drying, Lactobacillus plantarum 299v, Pediococcus acidilactici HA-6111-2, 37 maltodextrin, gum Arabic 


\section{Introduction}

47 The production of oranges in Portugal is more than 200,000 tons per year (OMAIAA, 2011) and

48 the possibility of producing natural orange juice powder would be an advantage at economic

49 level, not only by the reduction in volume and weight of the packages, easier transportation and

50 storage, but especially by increasing the shelf life of the product. At the same time, the use of

51 probiotics as food supplements is increasing, because of their health benefits, as well as the

52 increased diversity in food choices they provide. Presently, probiotics are defined as "live

53 microorganisms, which, when administered in adequate amounts, confer a health benefit on the

54 host" by the Food and Agriculture Organization of the United Nations and World Health

55 Organization (FAO/WHO, 2002). Producing an orange juice with probiotic bacteria can be an

56 innovative way to increase this diversity in food choices, especially among consumers who prefer

57 functional non-dairy based foods. Whilst dairy products are the priority for the development of

58 novel probiotic foods, an increase of vegetarianism, milk cholesterol content, and lactose

59 intolerance justify the need for non-dairy probiotic products (Granato et al., 2010).

60 Spray drying (SD) is the most common method used for converting liquid food products into dry

61 powder, because it is inexpensive and easy to operate. Briefly, the process involves the pumping

62 of liquid sample into the atomizer that transforms the liquid into small droplets, which rapidly

63 lose their moisture on contact with the hot and dry air (Silva et al., 2011). It could be a good

64 method to get a natural orange juice powder, if the characteristics of the natural juice allowed the

65 powder production. Fruit juices are extremely sticky, due to the presence of low molecular

66 weight sugars and organic acids in their composition, their high hygroscopicity, water solubility

67 and low melting point (Bhandari et al., 1997). The usual strategy to spray-dry sticky products is

68 the use of wall materials with high molecular weight. Several authors have been using drying aids

69 to a variety of fruit juices, being maltodextrins and gum Arabic the more common agents used 
70 (Martinelli et al., 2007; Tonon et al., 2010). Maltodextrins are low cost oligosaccharides, made

71 from starch, that have dextrose equivalents (DE) and gum Arabic is a complex

72 heteropolysaccharide and a natural exudate of Acacia tree (Bemiller \& Whistler, 1996). Together

73 with their ability as drying agents, several studies have provided evidence that both maltodextrin

74 and gum Arabic also have prebiotic effects (Anekella \& Orsat, 2013; Slavin, 2013). Prebiotics are

75 defined as "nondigestible food ingredients that beneficially affect the host by selectively

76 stimulating the growth and/or activity of one or a limited number of bacteria in the colon, thus

77 improving host health" (Gibson \& Roberfroid, 1995).

78 Studies on SD of fruit juices with probiotic bacteria incorporated are rare (Anekella \& Orsat,

79 2013; Pereira et al., 2014), probably because there are many factors influencing the survival of

80 probiotics before, during and after SD (reviewed by Barbosa et al., 2016).

81 This work aimed to develop an orange juice powder dried by SD and incorporating viable lactic

82 acid bacteria (LAB), ensuring their survival both during drying and storage.

\section{Materials and methods}

85 Origin, growth and storage conditions of LAB isolates

86 Two LAB were used: Lactobacillus plantarum 299v (Probis Probiotika, Lund, Sweden) and

87 Pediococcus acidilactici HA-6111-2 deposited in Escola Superior de Biotecnologia (ESB)

88 culture collection (Barbosa et al., 2015).

89 Growth and storage of isolates were done according to Barbosa et al. (2015).

90

91 Conditions of the drying process of orange juice

92 Materials 
93 Mature oranges exclusively originated in Portugal were randomly purchased from local

94 commercial establishments (Porto, Portugal) and stored at room temperature until used (for no

95 more than $24 \mathrm{~h}$ before experiments).

96 The drying agents used were 10 DE maltodextrin (Sigma, Steinheim, Germany) and gum Arabic

97 (Merck, Darmstadt, Germany).

98

99 Orange juice preparation

100 Oranges were squeezed using a domestic juicer and the juice was filtered in order to eliminate the 101 solids in suspension, preventing the obstruction of the atomizer of the spray dryer. The content of 102 the total soluble solids of the juice was measured using a digital refractometer (model PR-32 $\alpha$ 103 (alpha), Brix 0-32\%, Atago U.S.A., Inc., WA, U.S.A.) and adjusted to 0.5 or 1\% (w/v). The 104 drying agents $10 \mathrm{DE}$ maltodextrin and gum Arabic were added, both at the concentrations of 1 or $1052 \%(\mathrm{w} / \mathrm{v})$, under magnetic stirring at $40{ }^{\circ} \mathrm{C}$, until complete dissolution.

$107 \quad$ Spray drying

108 The drying of orange juice was performed in a laboratory scale Büchi Mini Spray Dryer Model

109 B-191 (Büchi Laboratoriums-Technik, Flawil, Switzerland) with a two-fluid nozzle atomizer

110 with a $1 \mathrm{~mm}$ inside diameter and a concurrent drying chamber of $10.5 \mathrm{~cm}$ (Barbosa et al., 2015).

111 The inlet air temperatures tested were 120 and $130{ }^{\circ} \mathrm{C}$. The outlet air temperature cannot be

112 regulated, resulting from a combination of the inlet air temperature, the feed rate, the drying gas

113 flow rate and the solids content of the feed. A single cyclone air separator system was used and 114 the dried powders were collected from the base of the cyclone.

115

116 Analysis of powders 
117 Immediately after the SD, drying yield and water activity $\left(\mathrm{a}_{\mathrm{w}}\right)$ of the dried powders were

118 determined (Barbosa et al., 2015).

119

\section{Spray drying of orange juice with LAB}

121 Orange juice preparation

122 The orange juice was prepared as described above. After the selected conditions, the total soluble

123 solids content of the juice was adjusted to $0.5 \%(\mathrm{w} / \mathrm{v})$ and at this solution was added $2 \%(\mathrm{w} / \mathrm{v})$ of

124 the drying agent (10 DE maltodextrin or gum Arabic), under magnetic stirring at $40{ }^{\circ} \mathrm{C}$, until

125 complete dissolution.

\section{Preparation of LAB cultures}

128 From Man, Rogosa and Sharpe (MRS) agar incubated at $37{ }^{\circ} \mathrm{C}$ for $24 \mathrm{~h}$, one colony of each LAB 129 isolate was transferred to MRS broth and incubated at the same conditions. For the final 130 inoculum, the last culture was transferred to a new MRS broth (1:100) and incubated at $37^{\circ} \mathrm{C}$ for $13124 \mathrm{~h}$ to reach stationary phase. Each isolate was harvested by centrifugation $(8877 \mathrm{x} \mathrm{g}, 10 \mathrm{~min}, 37$ $132{ }^{\circ} \mathrm{C}$; Rotina 35R, Hettich, Germany), washed twice in sterile quarter strength Ringer's solution 133 (Lab M, Bury, United Kingdom) and re-suspended in the same volume of the final solution 134 prepared before (in Orange Juice Preparation).

135 As control, 10\% (w/v) of reconstituted skim milk (RSM) powder (Oxoid, Basingstoke, UK) was 136 used to re-suspend the LAB cultures.

$138 \quad$ Spray drying and powder analysis

139 The drying of LAB cultures incorporated either in orange juice or in the RSM was achieved as 140 described above. The drying conditions chosen for both LAB cultures were: feed temperature of 
$14140^{\circ} \mathrm{C}$, feed flow rate of $5 \mathrm{~mL} / \mathrm{min} ; 86 \%$ of drying air flow rate; compressed air flow rate of 550

$142 \mathrm{~L} / \mathrm{h}$, inlet air temperature of $120^{\circ} \mathrm{C}$ and outlet air temperature of about $65^{\circ} \mathrm{C}$.

143 Drying yield and $\mathrm{a}_{\mathrm{w}}$ of the dried powders were also determined.

145 Storage conditions

146 Dried samples were stored in plastic containers, hermetically sealed in glass flasks, in normal

147 atmosphere (air), in the presence of daylight, at $4{ }^{\circ} \mathrm{C}$ and room temperature.

149 Enumeration of spray dried LAB cultures

150 The survival of each microorganism was assessed immediately after SD and at regular intervals

151 throughout storage by rehydration of each dried sample to their initial solids concentration in

152 sterile quarter strength Ringer's solution (Lab M). Each rehydrated sample was homogenized for

1531 minute and kept at room temperature for 30 minutes followed by serial decimal dilutions and

154 plated in duplicate for enumeration by the drop count technique (Miles and Misra, 1938) on MRS

155 agar. The enumeration of each microorganism re-suspended in both orange juice or RSM before

156 SD was also performed.

157 The colonies were counted after incubation at $37^{\circ} \mathrm{C}$ for $48 \mathrm{~h}$ and the $\mathrm{CFU} / \mathrm{mL}$ calculated.

\section{Data analysis}

160 Each experiment was done in duplicate. All calculations were carried out using the software IBM 161 SPSS Statistics (version 22.0, IBM Corporation, Armonk, NY, USA). A significance level of $P<$ 1620.05 was applied to all statistical procedures.

164 Statistical analysis 
165 Significant differences in microbial counts of each LAB before and after SD were analyzed using 166 a paired-samples t-test.

167 Microbial counts were transformed to logarithmic reduction using the equation: $\log \left(\mathbf{N} / \mathbf{N}_{\mathbf{0}}\right)$, 168 where $\mathrm{N}$ is the microbial cell count at a particular sampling time and $\mathrm{N}_{0}$ is the microbial cell 169 count after SD. To evaluate the values of the variable $\log \mathrm{N} / \mathrm{N}_{0}$ (between the first and the last 170 storage time) among different isolates and used treatments (different drying agents) studied, we 171 applied multivariate models of generalized estimating equations (GEE), with identity as binding 172 function, i.e., it was assumed a linear time course over the months of storage. The GEE are a 173 method that allow analyzing repeated or longitudinal measures, taking into account that the 174 measurements in the same individual over time are correlated. The advantage of this method is 175 that it provides consistent estimates of the parameters associated with covariances of the model, 176 even if the assumed correlation structure would be wrong.

178 Logistic model

179 Data from logarithmic reductions of each LAB along storage were adjusted with Logistic model 180 using the equation: $\log \left(\mathbf{N} / \mathbf{N}_{0}\right)=-\mathbf{C} /\left(\mathbf{1}+\mathbf{A e}^{-\mathbf{B}}\right)$, where $\mathrm{N}$ is the microbial cell count at a 181 particular sampling time, $\mathrm{N}_{0}$ is the microbial cell count after $\mathrm{SD}, \mathrm{C}$ is the asymptotic value, which 182 evaluates the tail tendency and B is related to the steepness of the curve (higher values are 183 associated to higher inactivation rates) (Chen, 2007).

\section{Results}

186 Powdered orange juice was initially obtained in a Büchi Mini Spray Dryer at i) constant feed 187 temperature $\left(40^{\circ} \mathrm{C}\right)$, flow rates of feed $(5 \mathrm{~mL} / \mathrm{min})$, drying air $(86 \%)$ and compressed air $(550$ $188 \mathrm{~L} / \mathrm{h})$ and ii) varying inlet air temperatures $\left(120\right.$ and $\left.130^{\circ} \mathrm{C}\right)$ as well as the ratio of total soluble 
189 solids (orange juice; 0.5 or $1 \% \mathrm{w} / \mathrm{v}$ ): drying aid (10DE maltodextrin or gum Arabic; 1 or $2 \%$

$190 \mathrm{w} / \mathrm{v}$ ). Powders with different drying yield and $\mathrm{a}_{\mathrm{w}}$ values were obtained (data not shown). In table

191 S1 are presented the drying yields and $\mathrm{a}_{\mathrm{w}}$ values obtained only for the selected conditions: inlet

192 and outlet air temperatures of $120^{\circ} \mathrm{C}$ and $65^{\circ} \mathrm{C}$, respectively, and ratio of soluble solids: drying

193 aid of $0.5: 2$. For both drying agents, drying yield was close to $50 \%$ and values of $\mathrm{a}_{\mathrm{w}}$ between 0.3

194 and 0.4 were obtained for the orange juice powders.

195

196 In table 1 are shown the $\log$ CFU/ml of L. plantarum 299v and P. acidilactici HA-6111-2 before

197 and after being spray dried. For each LAB, besides the strong correlation coefficient $(>0.9)$, no

198 significant differences were obtained $(P>0.05)$ between before and after the drying process.

199 Moreover, no logarithmic reductions were obtained after SD for both LAB.

201 Kinetic parameters for logarithmic reductions of each LAB along 210 days of storage at room 202 temperature and $4{ }^{\circ} \mathrm{C}$ are detailed in Table S2.

203 The survival of each microorganism during storage at room temperature is presented in Figure 1.

204 For both LAB, survival during storage at room temperature was higher when cells were spray

205 dried in RSM. Although, the reduction of both microorganisms had been lower for RSM initially,

206 both were reduced to values below the level of the detection limit of the enumeration technique

207 after 150 (L. plantarum 299v; graph A1) or 210 days of storage (P. acidilactici HA-6111-2;

208 graph B1).

209 In spray dried orange juice, significant differences were obtained between the drying agents used 210 regarding to the survival of LAB during storage period studied $(P<0.05)$. After 11 days of

211 storage in orange juice dried with $10 \mathrm{DE}$ maltodextrin (graph A2) an accentuated reduction in the 212 number of cells of L. plantarum 299v occurred, and after 60 days the logarithmic reduction was 
213 to values below the level of the detection limit of the enumeration technique. In orange juice

214 dried with gum Arabic (graph A3), even though the similar behavior, higher reduction in the

215 number of cells of L. plantarum 299v occurred initially, compared with orange juice dried with

$21610 \mathrm{DE}$ maltodextrin.

217 Despite survival of P. acidilactici HA-6111-2 dried in orange juice with 10 DE maltodextrin 218 (graph B2) or gum Arabic (graph B3) had been different along the storage period $(P<0.05)$, in

219 both cases, the reduction in the number of cells became more pronounced after 30 days of storage

220 and values below the level of the detection limit were attained after 120 days of storage.

221

222 In Figures 2 and $\mathrm{S} 1$ are presented the survival of L. plantarum 299v and P. acidilactici HA-6111-

2232 , respectively, during storage at $4{ }^{\circ} \mathrm{C}$. A higher survival was observed during storage at $4{ }^{\circ} \mathrm{C}$ than

224 at room temperature, for both LAB.

225 In the case of L. plantarum 299v, the drying with RSM (Fig 2, graph A4) also conferred a

226 protective effect during storage at $4{ }^{\circ} \mathrm{C}$, comparing with the other drying agents $(P<0.05)$.

227 Significant differences were also found among the additives used $(P<0.05)$. In the orange juice

228 dried with $10 \mathrm{DE}$ maltodextrin (Fig 2, graph A5), there was a 4 log-units reduction in the survival

229 of L. plantarum $299 \mathrm{v}$ up to 90 days of storage and of $8 \log$-units until the end of the storage

230 period (210 days). In the presence of gum Arabic (Fig 2, graph A6), after this period of 90 days

231 this reduction was higher than in the presence of $10 \mathrm{DE}$ maltodextrin, reaching values below the

232 detection limit after 210 days (>9.9 log reduction).

233 No significant differences were observed in the survival of $P$. acidilactici HA-6111-2 during

234 storage at $4{ }^{\circ} \mathrm{C}(P>0.05)$ for all the SD media investigated, RSM (Fig S1, graph B4) and orange

235 juice supplemented with 10 DE maltodextrin (Fig S1, graph B5) or gum Arabic (Fig S1, graph 
236 B6). At this storage temperature, P. acidilactici HA-6111-2 demonstrated a higher survival than

237 L. plantarum 299v $(P<0.05)$, showing less than 1 log-unit reduction after 210 days.

238 Orange juice dried with $10 \mathrm{DE}$ maltodextrin conferred a slightly higher protection on the survival 239 of L. plantarum $299 \mathrm{v}$ during storage at $4{ }^{\circ} \mathrm{C}$.

\section{Discussion}

242 To develop a new product such as an orange juice powder with functional properties, two LAB

243 were selected to be incorporated: L. plantarum 299v - a commercial probiotic and P. acidilactici

244 HA-6111-2 an isolated strain from a food matrix and with probiotic characteristics found after

245 preliminary characterization (Barbosa et al., 2015).

247 Optimization of a drying process is the initial step to gather the best conditions for obtaining a

248 powdered product of good quality. The different parameters evaluated to optimize the drying

249 process of orange juice by SD were i) the content of soluble solids in orange juice, as well as the

250 optimal ratio of drying agents tested, allowing the juice drying with the lowest loss of powder,

251 and ii) the inlet air temperature of the SD. With the different tests carried out, conditions leading

252 to the highest drying yield and product with low $\mathrm{a}_{\mathrm{w}}$ were selected: $0.5: 2$ ratio of the orange juice

253 soluble solids and drying agent added.

254 Another important parameter in SD is the outlet air temperature. As previously mentioned, in the

255 Büchi Mini Spray Dryer used this is not an adjustable parameter, resulting from the combination

256 of the various parameters such as inlet air temperature, pump and aspirator settings and feed

257 concentration. Several researchers reported that outlet air temperatures above $85^{\circ} \mathrm{C}$ were lethal

258 for probiotic cultures (Gardiner et al., 2000; Corcoran et al., 2004). Since we intended to

259 incorporate probiotics into orange juice and the outlet air temperatures are such an important 
260 parameter in the survival of bacteria during drying, all the conditions selected (Table S1) resulted

261 in low outlet air temperatures (close to $65^{\circ} \mathrm{C}$ ) and, simultaneously, high drying yields and low $\mathrm{a}_{\mathrm{w}}$

262 values.

263 According to Bhandari et al. (1997) a total powder recovery of 50\% in a laboratory scale spray

264 dryer is considered to be the reference point for a marginally successful drying. From both

265 concentrations of the drying agents tested, the addition of $2 \%(\mathrm{w} / \mathrm{v})$ to the orange juice allowed a

266 better drying yield than $1 \%(\mathrm{w} / \mathrm{v})$. This is in agreement with some studies which stated that the

267 increasing of drying agents concentration in fruit juices, also increased the powder yield (Quek et

268 al., 2007; Fazaeli et al., 2012). With the subsequent addition of probiotic cultures to orange juice,

269 it was important that the selected conditions allowed to obtain low $\mathrm{a}_{\mathrm{w}}$ values, as water remaining

270 after drying affects the viability of cultures, after the drying process and also during storage

271 (Zayed \& Roos, 2004). Moreover, dried products with $\mathrm{a}_{\mathrm{w}}$ values below 0.6 are considered

272 microbiologically stable (Quek et al., 2007).

273

274 After the selection of SD conditions for orange juice powder production, we proceeded to the

275 incorporation of each LAB to the juice with each drying agent - 10 DE maltodextrin and gum

276 Arabic - and subsequent drying. The survival of LAB was not affected during the drying process

$277(P>0.05)$. Good survival of probiotics after SD in fruit juices had already been reported

278 (Anekella \& Orsat, 2013).

279

280 Drying of the selected LAB in RSM was used as a control since it has been demonstrated that it

281 is as an efficient protector, both during drying and also during subsequent storage (Teixeira et al., 282 1995a; Gardiner et al., 2000; Ananta et al., 2005).

283 
284 As expected, significant differences were obtained between the temperatures of storage used $(P<$ 285 0.05). Many authors reported the higher survival of spray dried bacteria during storage at low 286 temperatures (Teixeira et al., 1995b; Gardiner et al., 2000; Silva et al., 2002).

287 Of the drying agents used in this study, $10 \mathrm{DE}$ maltodextrin allowed better results on the survival 288 of L. plantarum 299v in comparison with gum Arabic. Other studies have demonstrated the 289 importance of maltodextrin as a drying agent in fruit juices, as well as its protective ability of 290 probiotic cultures during drying and subsequent storage (Anekella \& Orsat, 2013; Pereira et al., 291 2014).

292 Despite the scarce literature regarding the drying of L. plantarum and P. acidilactici strains 293 incorporated in fruit juices by SD, many authors have studied the behavior of different strains 294 after SD using maltodextrin as carrier. Lapsiri et al. (2012) found high survival rate of $L$.

295 plantarum TISTR 2075 after SD. During storage at different temperatures, survival of spray dried 296 cells was affected by elevated temperatures; while at $25^{\circ} \mathrm{C}$ no cells have survived up to 90 days 297 of storage, at $4{ }^{\circ} \mathrm{C}$ this strain had a decrease of only $1.62 \log \mathrm{CFU} / \mathrm{g}$ after $12 \mathrm{months}$ of storage in 298 the absence of light. In the study of Reddy et al. (2009), using maltodextrin and nonfat skimmed 299 as carriers, during 60 days of storage, the high temperatures also affected the survival rate of $L$.

300 plantarum and $P$. acidilactici strains tested. At $4{ }^{\circ} \mathrm{C}$ a survival rate of $60 \%$ was obtained for both

301 strains and carriers. At $30{ }^{\circ} \mathrm{C}$, using maltodextrin as carrier, the survival rate decreased to $50 \%$ for 302 both strains and using nonfat skimmed, the survival rate decreased to $67 \%$ for L. plantarum and 303 to $53 \%$ for $P$. acidilactici. The authors concluded that maltodextrin is a good substitute of nonfat 304 skimmed.

305 Although maltodextrin could be a good encapsulating agent during SD, it also acts as a prebiotic, 306 allowing the survival of the cultures (Reddy et al., 2009; Lapsiri et al., 2012; Anekella \& Orsat, 307 2013; Pereira et al., 2014). 
308 In this study, and only focusing the results obtained during storage at $4{ }^{\circ} \mathrm{C}$, it was possible to

309 obtain spray dried cultures in orange juice, which could survive and remain viable in amounts of

$31010^{7} \mathrm{CFU} / \mathrm{ml}$, over a certain period of time. As expected, different microorganisms had different

311 behaviors: while the orange juice powder contained $10^{7} \mathrm{CFU} / \mathrm{mL}$ of L. plantarum $299 \mathrm{v}$ only up

312 to 90 days of storage at $4{ }^{\circ} \mathrm{C}$, the orange juice powder with $P$. acidilactici HA-6111-2 contained

$31310^{8} \mathrm{CFU} / \mathrm{mL}$, at least up to 210 days of storage. This means that the conditions are fulfilled for

314 extra and important experiments being performed, especially in terms of i) storage conditions

315 improvement, ii) validation of results in a larger industrial drier and iii) validation of the ability

316 of the dried probiotic cultures to retain its functional properties. Nonetheless, the present data is

317 promising and allowed to prove that it is possible to produce a functional non-dairy based food,

318 such as an orange juice powder that incorporates probiotic ingredients.

320 Conclusions

321 The conditions to obtain orange juice powder by SD were pooled. Another challenge was the

322 incorporation of bacteria with probiotic characteristics and that they were able to survive during

323 drying process and storage. In this study it was demonstrated that it is possible to produce a

324 healthy product, not only for the advantage of using a powder made from natural fruit juice, as

325 well as the beneficial characteristics conferred by a prebiotic and probiotic incorporated.

326 Within various additives which can be used in food industry, the prebiotic maltodextrin turned

327 possible not only to obtain a powder of good quality, but also a higher survival of one of the

328 bacteria incorporated into orange juice, along its storage at $4{ }^{\circ} \mathrm{C}$. If this product is stored and sold

329 at refrigerated conditions it can have a long shelf life, depending on the probiotic used. The

330 potential probiotic $P$. acidilactici HA-6111-2 studied was more resistant than the probiotic $L$.

331 plantarum 299v. The challenge continues to be the preservation of these products at room 
332 temperature, so it is necessary to improve the storage conditions in order to increase their shelf

333 life at the lowest possible cost.

335 Acknowledgments

336 This work was supported by funding from the National Funds from the Fundação para a Ciência

337 e a Tecnologia (FCT) through project UID/Multi/50016/2013. Financial support for author J.

338 Barbosa was provided by a post-doctoral fellowship, SFRH/BPD/113303/2015 (FCT).

339

$340 \quad$ References

341 Ananta, E., Volkert, M. \& Knorr, D. (2005). Cellular injuries and storage stability of spray-dried 342 Lactobacillus rhamnosus GG. International Dairy Journal, 15, 399-409.

343 Anekella, K. \& Orsat, V. (2013). Optimization of microencapsulation of probiotics in raspberry

$344 \quad$ juice by spray drying. LWT - Food Science and Technology, 50, 17-24.

345 Barbosa, J., Borges, S. \& Teixeira, P. (2015). Pediococcus acidilactici as a potential probiotic to 346 be used in food industry. International Journal of Food Science and Technology, 50, 1151$347 \quad 1157$.

348 Barbosa, J. \& Teixeira, P. (2016). Development of probiotic fruit juice powders by spray drying: $349 \quad$ a review. Food Reviews International, DOI: 10.1080/87559129.2016.1175016.

350 Bemiller, J.N. \& Whistler, R.L. (1996). Carbohydrates. In: Fenema, O.R. (Ed). Food Chemistry. $351 \quad$ New York: Marcel Dekker.

352 Bhandari, B.R., Datta, N. \& Howes, T. (1997). Problems associated with spray drying of sugar353 rich foods. Drying Technology, 15, 671-684.

354 Chen, H. (2007). Use of linear, Weibull, and log-logistic functions to model pressure 355 inactivation of seven foodborne pathogens in milk. Food Microbiology, 24, 197-204. 
356 Corcoran, B.M., Ross, R.P., Fitzgerald, G.F. \& Stanton, C. (2004). Comparative survival of

357 probiotic lactobacilli spray-dried in the presence of prebiotic substances. Journal of Applied

$358 \quad$ Microbiology, 96, 1024-1039.

359 Fazaeli, M., Emam-Djomeh, Z., Ashtari, A.K. \& Omid, M. (2012). Effect of spray drying

360 conditions and feed composition on the physical properties of black mulberry juice powder.

361 Food and Bioproducts Processing, 90, 667-675.

362 Food and Agriculture Organization/World Health Organization. Guidelines for the evaluation of

363 probiotics in food: Report of a joint FAO/WHO working group on drafting guidelines for

364 the evaluation of probiotics in food. London, ON, Canada, 2002.

365 Gardiner, G.E., O’Sullivan, E., Kelly, J. et al. (2000). Comparative survival rates of human-

366 derived probiotic Lactobacillus paracasei and L. salivarius strains during heat treatment

367 and spray-drying. Applied and Environmental Microbiology, 66, 2605-2612.

368 Gibson, G.R. \& Roberfroid, M.B. (1995). Dietary modulation of the human colonic microbiota:

369 Introducing the concept of prebiotics. Journal of Nutrition, 125, 1401-1412.

370 Granato, D., Branco, G.F., Nazzaro, F., Cruz, A.G. \& Faria, J.A.F. (2010). Functional foods and

371 nondairy probiotic food development: trends, concepts, and products. Comprehensive

372 Reviews in Food Science and Food Safety, 9, 292-302.

373 Lapsiri, W., Bhandari, B. \& Wanchaitanawong, P. (2012). Viability of Lactobacillus plantarum

374 TISTR 2075 in different protectants during spray drying and storage. Drying Technology,

$375 \quad 30,1407-1412$.

376 Martinelli, L., Gabas, A.L. \& Telis-Romero, J. (2007). Thermodynamic and quality properties of

377 lemon juice powder as affected by maltodextrin and arabic gum. Drying Technology, 25,

$378 \quad 2035-2045$. 
379 Miles, A.A. \& Misra, S.S. (1938). The estimation of the bactericidal power of blood. Journal of $380 \quad$ Hygiene, 38, 732-749.

381 Observatório dos mercados agrícolas e das importações agro-alimentares (OMAIAA). Retrieved 382 on July $2^{\text {nd }}, 2016$ from website: http://www.observatorioagricola.pt/item.asp?id_item=129. 383 Pereira, A.L.F., Almeida, F.D.L., Lima, M.A., Costa, J.M.C. \& Rodrigues, S. (2014). Spray384 drying of probiotic cashew apple juice. Food Bioprocess Technology, 7, 2492-2499.

385 Quek, S.Y., Chok, N.K. \& Swedlund, P. 2007. The physicochemical properties of spray-dried $386 \quad$ watermelon powders. Chemical Engineering and Processing, 46, 386-392.

387 Reddy, K.B.P.K., Madhu, A.N. \& Prapulla, S.G. (2009). Comparative survival and evaluation of 388 functional probiotic properties of spray-dried lactic acid bacteria. International Journal of 389 Dairy Technology, 62, 240-248.

390 Silva, J., Carvalho, A.S., Teixeira, P. \& Gibbs, P.A. (2002). Bacteriocin production by spray391 dried lactic acid bacteria. Letters in Applied Microbiology, 34, 77-81.

392 Silva, J., Freixo, R., Gibbs, P. \& Teixeira, P. (2011). Spray-drying for the production of dried 393 cultures. International Journal of Dairy Technology, 64, 321-335.

394 Slavin, J. (2013). Fiber and Prebiotics: Mechanisms and Health Benefits. Nutrients, 5, 1417$395 \quad 1435$.

396 Teixeira, P., Castro, H. and Kirby, R. (1995a). Spray drying as a method for preparing 397 concentrated cultures of Lactobacillus bulgaricus. Journal of Applied Bacteriology, 78, $398 \quad 456-462$.

399 Teixeira, P.C., Castro, M.H., Malcata, F.X. \& Kirby, R.M. (1995b). Survival of Lactobacillus 400 delbrueckii ssp. bulgaricus following spray-drying. Journal of Dairy Science, 78, 1025401 1031. 
1

2

3

4

402 Tonon, R.V., Brabet, C. \& Hubinger, M.D. (2010). Anthocyanin stability and antioxidant activity

403 of spray-dried acai (Euterpe oleracea Mart.) juice produced with different carrier agents.

$404 \quad$ Food Research International, 43, 907-914.

405 Zayed, G. \& Roos, Y.H. (2004). Influence of trehalose and moisture content on survival of

406 Lactobacillus salivarius subjected to freeze drying and storage. Process Biochemistry, 39,

$407 \quad$ 1081-1086.

408

409

410

411

412

413

414

415

416

417

418

419

420

421

422

423

424

425 
2
426 Table 1. Survival of L. plantarum 299v and P. acidilactici HA-6111-2 before and after SD in

427 RSM and orange juice supplemented with 10DE maltodextrin or gum Arabic

\begin{tabular}{|c|c|c|c|c|c|c|}
\hline & \\
\hline & \multicolumn{3}{|c|}{ L. plantarum 299v } & \multicolumn{3}{|c|}{ P. acidilactici HA-6111-2 } \\
\hline & RSM & $\begin{array}{c}10 \mathrm{DE} \\
\text { maltodextrin }\end{array}$ & $\begin{array}{c}\text { gum } \\
\text { Arabic }\end{array}$ & RSM & $\begin{array}{c}10 \mathrm{DE} \\
\text { maltodextrin }\end{array}$ & $\begin{array}{c}\text { gum } \\
\text { Arabic }\end{array}$ \\
\hline $\begin{array}{l}\text { Before } \\
\text { SD }\end{array}$ & $10.0 \pm 0.09$ & $10.0 \pm 0.53$ & $9.4 \pm 0.44$ & $10.7 \pm 0.29$ & $9.0 \pm 0.07$ & $9.1 \pm 0.04$ \\
\hline After SD & $11.3 \pm 0.10$ & $11.2 \pm 0.05$ & $9.9 \pm 0.70$ & $11.0 \pm 0.11$ & $9.1 \pm 0.23$ & $9.9 \pm 0.15$ \\
\hline
\end{tabular}


2

431 Figure 1. Logarithmic reduction (•) and Logistic model (-) of L. plantarum $299 \mathrm{v}(\mathbf{A})$ and $P$.

432 acidilactici HA-6111-2 (B) incorporated in orange juice or RSM after SD and during 210 days of

433 storage at room temperature: ( $\bullet-)$ control (inoculum in 10\% (w/v) of RSM); ( $\bullet-)$ orange

434 juice with $2 \%$ of $10 \mathrm{DE}$ maltodextrin and (- ) orange juice with $2 \%$ of gum Arabic. The

435 dotted lines mean that the isolate was reduced to values below the detection limited of the

436 enumeration technique.

437

438

439 Figure 2. Logarithmic reduction (•) and Logistic model (-) of L. plantarum 299v (A)

440 incorporated in orange juice or RSM after SD and during 210 days of storage at temperature of 4

$441{ }^{\circ} \mathrm{C}:(\rightarrow-)$ control (inoculum in $10 \%(\mathrm{w} / \mathrm{v})$ of RSM); $(\rightarrow-)$ ) orange juice with $2 \%$ of $10 \mathrm{DE}$

442 maltodextrin and $(-)$ ) orange juice with $2 \%$ of gum Arabic.

445 Figure S1. Logarithmic reduction ( $\bullet$ ) of $P$. acidilactici HA-6111-2 (B) incorporated in orange

446 juice or RSM after SD and during 210 days of storage at temperature of $4{ }^{\circ} \mathrm{C}:(\rightarrow-)$ control

447 (inoculum in 10\% (w/v) of RSM); ( $\bullet-)$ orange juice with $2 \%$ of 10 DE maltodextrin and

448 ( - ) orange juice with $2 \%$ of gum Arabic. Logistic model was not applied to this data.

449

Table S2. Formal kinetic parameters for logarithmic reductions of each LAB along storage 451 
Table S1. Yield and $\mathrm{a}_{\mathrm{w}}$ of orange juice powder at selected drying conditions

\begin{tabular}{|c|c|c|}
\hline \multirow{2}{*}{ Drying agent } & \multicolumn{2}{|c|}{ Orange juice $(0.5 \%$ of total soluble solids $)$} \\
\hline & Yield $^{\mathrm{a}}$ & $\mathbf{a}_{\mathbf{w}}{ }^{b}$ \\
\hline 2\% 10DE Maltodextrin & $40.90 \pm 1.13$ & $0.409 \pm 0.004$ \\
\hline 2\% gum Arabic & $53.05 \pm 1.48$ & $0.321 \pm 0.021$ \\
\hline \multicolumn{3}{|c|}{$\begin{array}{l}\text { a The powder yield is repres } \\
\text { standard error of the mean }\end{array}$} \\
\hline
\end{tabular}


Table S2. Formal kinetic parameters for logarithmic reductions of each LAB along storage

\begin{tabular}{|c|c|c|c|c|c|}
\hline \multirow[b]{2}{*}{ Condition } & \multirow[b]{2}{*}{ Parameters } & \multicolumn{2}{|c|}{ L. plantarum 299v } & \multicolumn{2}{|c|}{ P. acidilactici HA-6111-2 } \\
\hline & & Room temperature & $4{ }^{\circ} \mathrm{C}$ & Room temperature & $4^{\circ} \mathrm{C}$ \\
\hline \multirow{4}{*}{$\begin{array}{c}\text { RSM } \\
\text { (control) }\end{array}$} & $\mathrm{A} \pm \mathrm{IC} / 2$ & $7.035 \pm 2.903$ & $4.056 \pm 3.630$ & $10.895 \pm 4.057$ & \multirow{4}{*}{$\mathrm{n} / \mathrm{a}$} \\
\hline & $\mathrm{B} \pm \mathrm{IC} / 2$ & $0.028 \pm 0.007$ & $0.012 \pm 0.010$ & $0.025 \pm 0.005$ & \\
\hline & $\mathrm{C} \pm \mathrm{IC} / 2$ & $11.987 \pm 1.112$ & $5.624 \pm 4.754$ & $11.866 \pm 1.299$ & \\
\hline & $\mathrm{R}^{2}$ & 0.963 & 0.828 & 0.977 & \\
\hline \multirow{4}{*}{$\begin{array}{l}\text { Orange juice } \\
\text { with } 2 \% \text { of } \\
\text { 10DE MD }\end{array}$} & $\mathrm{A} \pm \mathrm{IC} / 2$ & $15.092 \pm 18.495$ & $6.264 \pm 4.053$ & $35.947 \pm 26.417$ & \multirow{4}{*}{$\mathrm{n} / \mathrm{a}$} \\
\hline & $\mathrm{B} \pm \mathrm{IC} / 2$ & $0.357 \pm 0.151$ & $0.015 \pm 0.011$ & $0.070 \pm 0.014$ & \\
\hline & $\mathrm{C} \pm \mathrm{IC} / 2$ & $10.232 \pm 0.556$ & $10.344 \pm 6.223$ & $9.051 \pm 0.322$ & \\
\hline & $\mathrm{R}^{2}$ & 0.939 & 0.842 & 0.990 & \\
\hline \multirow{4}{*}{$\begin{array}{c}\text { Orange juice } \\
\text { with } 2 \% \text { of } \\
\text { GA }\end{array}$} & $\mathrm{A} \pm \mathrm{IC} / 2$ & $25.223 \pm 18.131$ & $19.137 \pm 13.238$ & $83.619 \pm 107.016$ & \multirow{4}{*}{$\mathrm{n} / \mathrm{a}$} \\
\hline & $\mathrm{B} \pm \mathrm{IC} / 2$ & $0.456 \pm 0.100$ & $0.026 \pm 0.009$ & $0.067 \pm 0.020$ & \\
\hline & $\mathrm{C} \pm \mathrm{IC} / 2$ & $9.862 \pm 0.263$ & $10.557 \pm 1.808$ & $10.028 \pm 0.502$ & \\
\hline & $\mathrm{R}^{2}$ & 0.985 & 0.958 & 0.983 & \\
\hline
\end{tabular}

Legend: B - related to the steepness of the curve; $\mathrm{C}$ - the asymptotic value $\mathrm{n} / \mathrm{a}-$ not applicable 
A1

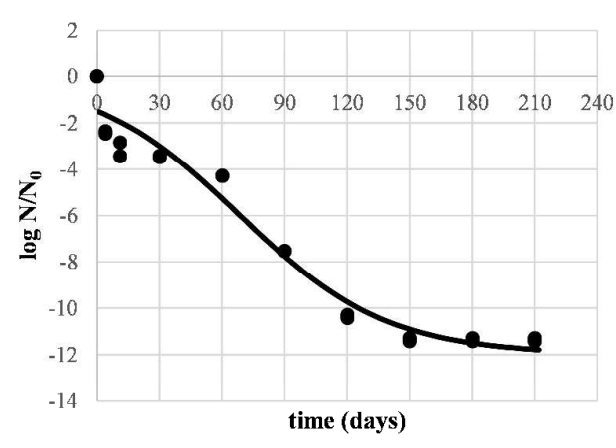

A2

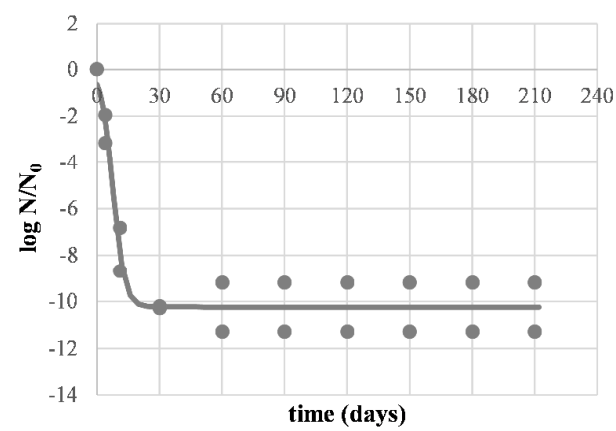

A3

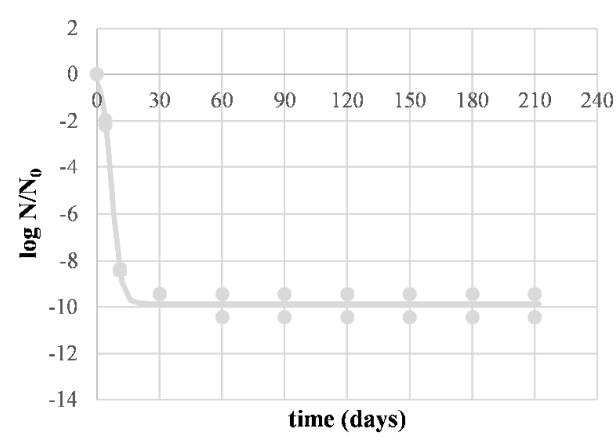

B1

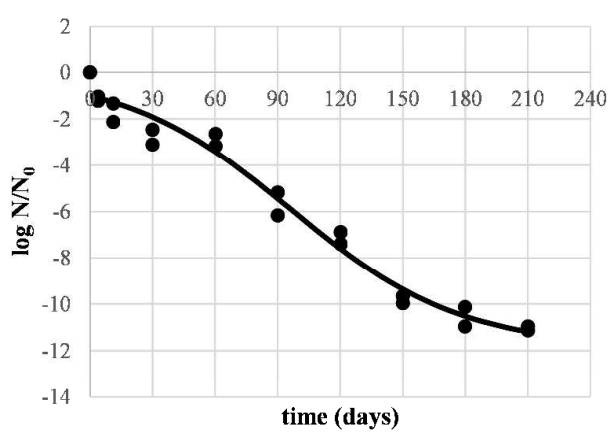

B2

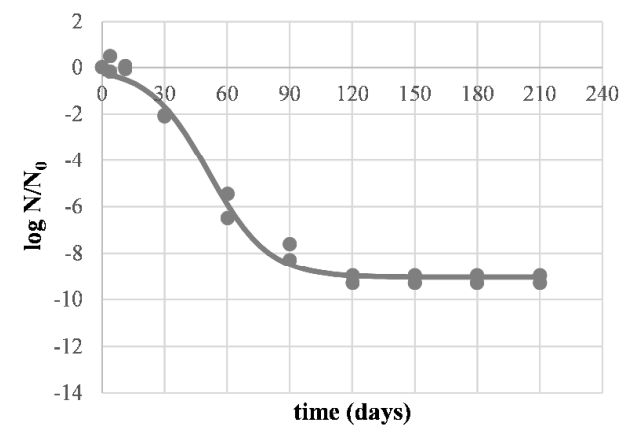

B3

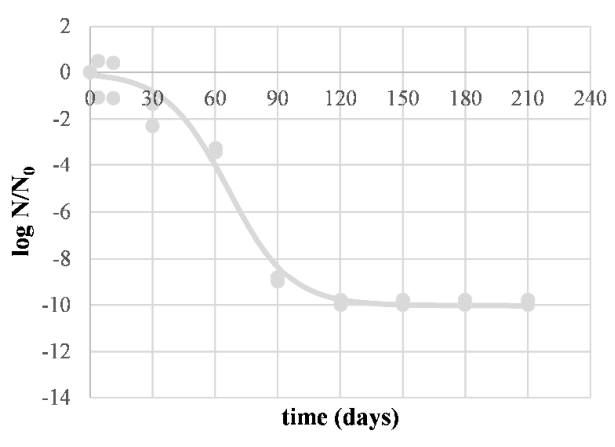

Figure 1. 

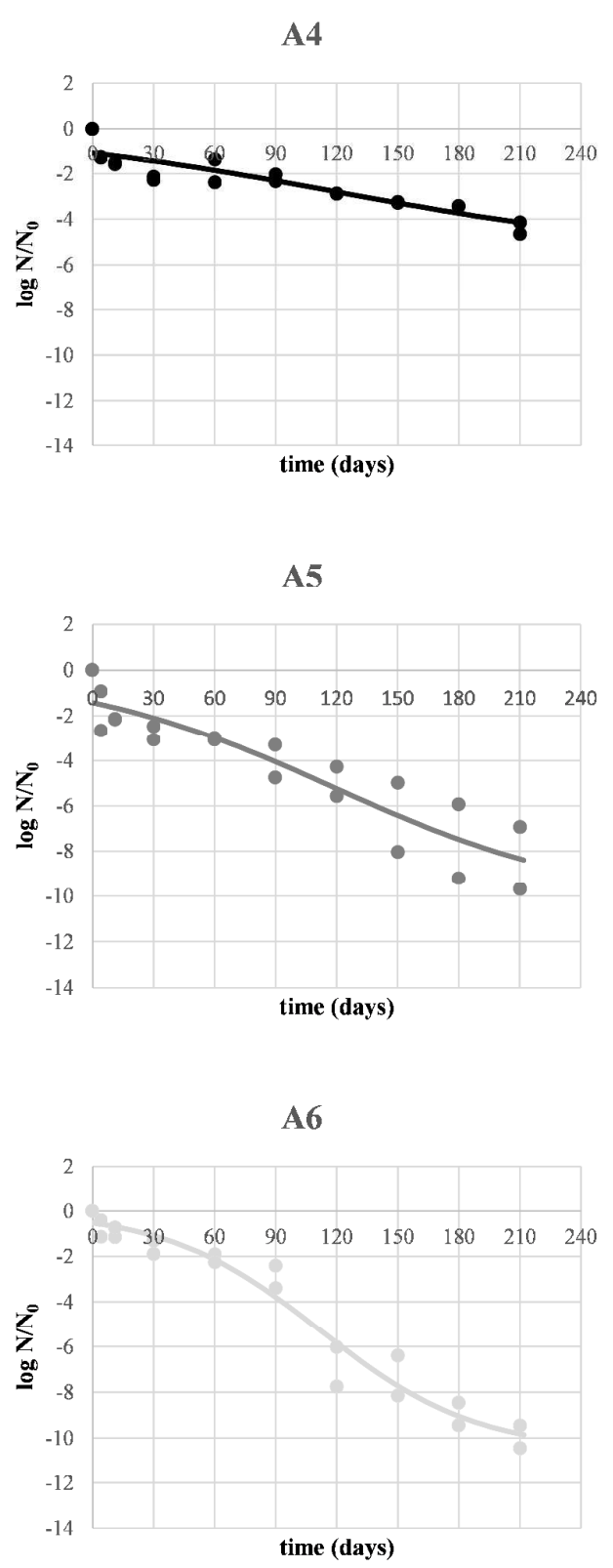

Figure 2. 

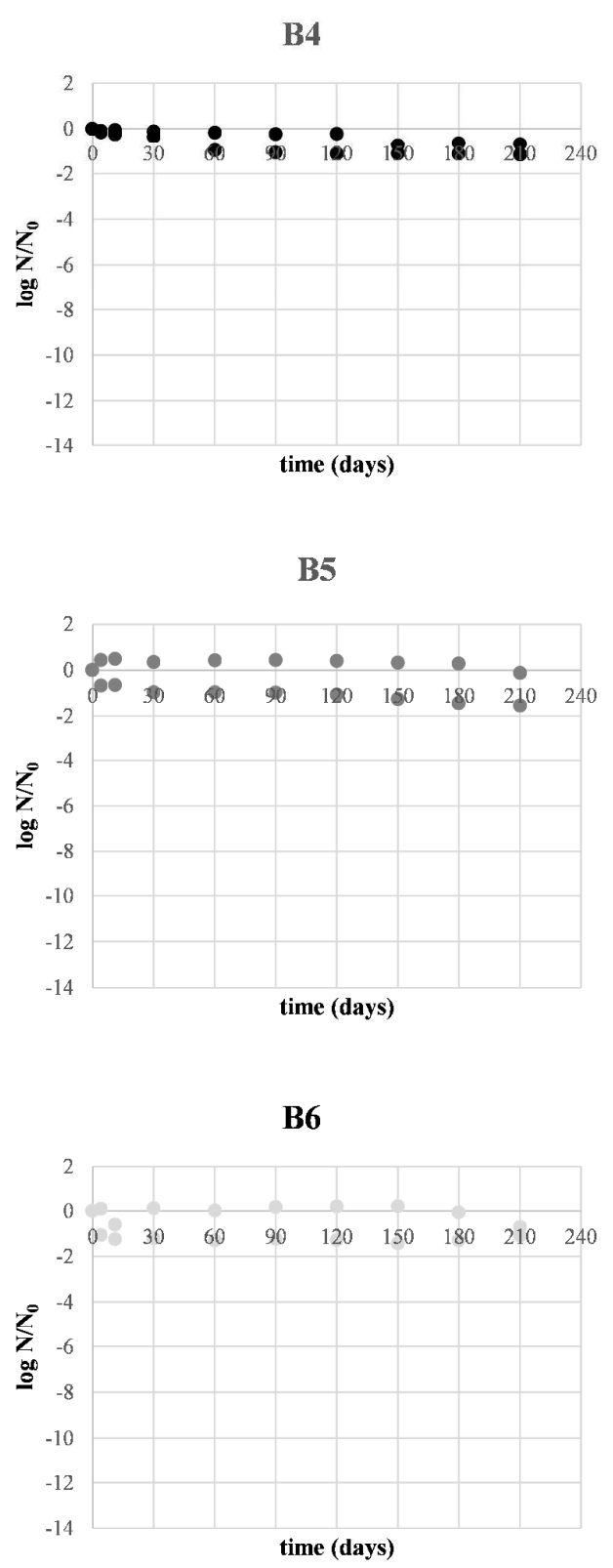

Figure S1. 